\section{Commentary: How to avoid early Fontan failure?}

\author{
Michelle Mizrahi, MD, and Ziv Beckerman, MD
}

We congratulate Quail and colleagues ${ }^{1}$ for their article in this issue of the Journal and their efforts to advance this complex field of single-ventricle palliation. Currently, the Fontan procedure, or total cavopulmonary connection (TCPC), serves as the last step of palliation for several single-ventricle congenital heart conditions. ${ }^{2}$ It allows for the entire systemic venous return to passively flow to the pulmonary arterial tree without an interposed pump. ${ }^{3}$ Several requirements must be met for TCPC to be successful (some well-known, others still being explored), necessitating extensive and meticulous evaluation of pre-Fontan patients.

The current common practice of pre-TCPC evaluation is aimed at providing an in-depth physiological understanding of the prospective Fontan candidate, with one of the goals being to avoid, among several other complications, early Fontan failure (EFF). EFF is a devastating scenario following TCPC that presents with low cardiac output and elevated central venous pressure (CVP). ${ }^{4}$

During this evaluation, patients usually undergo echocardiography, cardiac catheterization, and computed tomography or cardiovascular magnetic resonance (CMR). Although some centers have a wide implementation of preoperative cardiac catheterization, ${ }^{2}$ others do not. ${ }^{5}$ Cardiac catheterization provides precise hemodynamic and physiological parameters of the patient being evaluated.

In their study, Quail and colleagues attempted to omit the pre-TCPC catheterization, using a different approach to predict post-TCPC CVP $\left(\mathrm{CVP}_{\mathrm{TCPC}}\right)$. It is generally accepted that elevated CVP after TCPC is associated with

\footnotetext{
From the Texas Center for Pediatric and Congenital Heart Disease, UT Health Austin/Dell Children's Medical Center; and Department of Surgery and Perioperative Care, University of Texas at Austin Dell Medical School, Austin, Tex.

Disclosures: The authors reported no conflicts of interest.

The Journal policy requires editors and reviewers to disclose conflicts of interest and to decline handling or reviewing manuscripts for which they may have a conflict of interest. The editors and reviewers of this article have no conflicts of interest.

Received for publication June 25, 2020; revisions received June 25, 2020; accepted for publication July 1, 2020; available ahead of print July 11, 2020.

Address for reprints: Ziv Beckerman, MD, 4900 Mueller Blvd, Suite 3S.003, Austin, TX 78723 (E-mail: zbeckerman@austin.utexas.edu).

J Thorac Cardiovasc Surg 2021;161:1435-6

$0022-5223 / \$ 36.00$

Copyright (c) 2020 by The American Association for Thoracic Surgery

https://doi.org/10.1016/j.jtcvs.2020.07.007
}

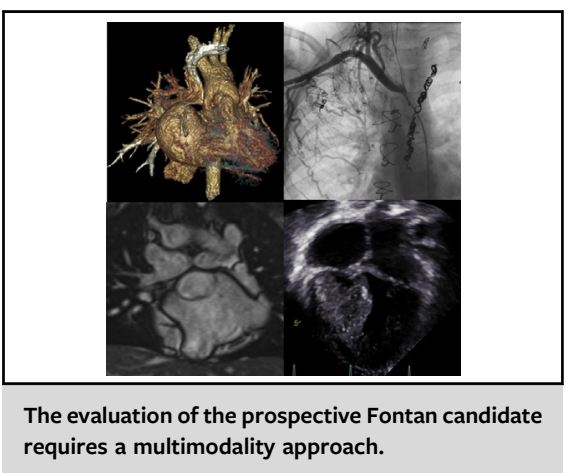

\section{CENTRAL MESSAGE \\ Our goal should be to achieve a zero percent rate of early and late Fontan failure.}

Fontan failure. ${ }^{4}$ The authors used information gathered from a pre-TCPC CMR, along with the CVP measured via jugular venipuncture at the same time, to predict the $\mathrm{CVP}_{\mathrm{TCPC}}$.

Although the authors did not demonstrate a perfect correlation between the predicted and actual post-TCPC CVP, they did find a consistent association between the predicted CVP $_{\text {TCPC }}$ and EFF. They concluded that estimated $\mathrm{CVP}_{\mathrm{TCPC}}$ can help guide important clinical decisions, such as creating a preemptive TCPC fenestration (reserved by some institutions for high-risk patients). ${ }^{6}$ It should be mentioned that the rate of elective TCPC fenestration in this study was rather high $(41 \%)$.

The authors should be congratulated for this important contribution to the body of knowledge, and for providing us with additional tools in our everlasting attempt to better define the ideal hemodynamics for Fontan patients. Owing to the critical importance of this palliative step and its potential morbid and/or fatal complications, it is our practice and recommendation to undertake elaborate and comprehensive preoperative evaluation for all patients. We recommend continuing to perform pre-TCPC catheterization, as well as taking a highly targeted approach to TCPC fenestration. The value of $\mathrm{CVP}_{\mathrm{TCPC}}$ can very well be added to our armamentarium.

The ultimate goal should be to have an early Fontan failure rate of zero percent.

\section{References}

1. Quail MA, Chan I, Sarna S, Hughes M, Muthurangu V. A preoperative estimate of central venous pressure is associated with early Fontan failure. J Thorac Cardiovasc Surg. 2021;161:1426-34. 
2. Mery CM, De León LE, Trujillo-Diaz D, Ocampo EC, Dickerson HA, Zhu H, et al. Contemporary outcomes of the Fontan operation: a large single-institution cohort. Ann Thorac Surg. 2019;105:1439-46.

3. Mori M, Aguirre AJ, Elder RW, Kashkouli A, Farris AB, Ford RM, et al. Beyond a broken heart: circulatory dysfunction in the failing Fontan. Pediatr Cardiol. 2014; 35:569-79.

4. Chaudhari M, Sturman J, O'Sullivan J, Smith J, Wrightson N, Parry G, et al. Rescue cardiac transplantation for early failure of the Fontan-type circulation in children. $J$ Thorac Cardiovasc Surg. 2005;129:416-22.

5. Rychik J, Atz AM, Celermajer DS, Deal BJ, Gatzoulis MA, Gewillig MH, et al. Evaluation and management of the child and adult with Fontan circulation: a scientific statement from the American Heart Association. Circulation. 2019;140:e234-84.

6. Salazar JD, Zafar F, Siddiqui K, Coleman RD, Morales DLS, Heinle JS, et al. Fenestration during Fontan palliation: now the exception instead of the rule. J Thorac Cardiovasc Surg. 2010;140:129-36.
See Article page 1426

\section{Commentary: If only we knew when we would fail}

\author{
Manan H. Desai, MD, and Can Yerebakan, MD
}

Approximately 5 decades ago, Fontan and colleagues ${ }^{1}$ gave a new lease on life to patients with single ventricle physiology by introducing a novel surgical procedure. Soon after the total cavopulmonary connection (TCPC) surgery was designed, it was realized that patient selection was critical for the success of the procedure; thus, the commandments of the Fontan procedure were introduced. ${ }^{2}$ As the procedure underwent several modifications and perioperative management improved, contraindications of the procedure were liberalized.

In this issue of the Journal, Quaila and colleagues ${ }^{4}$ have tried to address the problem of predicting early Fontan failure. They retrospectively reviewed the imaging and clinical data of 131 patients who had undergone total cavopulmonary circulation. In the first part of the study, they created and validated a formula to predict postoperative hemodynamic data using preoperative cardiac magnetic resonance (CMR) imaging. The calculated post-TCPC central venous pressure (CVP) correlated well with the

\footnotetext{
From the Department of Cardiovascular Surgery, Children's National Heart Institute, Children's National Hospital, The George Washington University School of Medicine and Health Sciences, Washington, DC.

Disclosures: The authors reported no conflicts of interest.

The Journal policy requires editors and reviewers to disclose conflicts of interest and to decline handling or reviewing manuscripts for which they may have a conflict of interest. The editors and reviewers of this article have no conflicts of interest.

Received for publication July 18, 2020; revisions received July 18, 2020; accepted for publication July 20, 2020; available ahead of print July 23, 2020.

Address for reprints: Manan H. Desai, MD, Department of Cardiovascular Surgery, Children's National Heart Institute, Children's National Hospital, 111 Michigan Ave NW, Washington, DC 20010 (E-mail: mdesai2@childrensnational.org).

J Thorac Cardiovasc Surg 2021;161:1436-7

$0022-5223 / \$ 36.00$

Copyright (c) 2020 by The American Association for Thoracic Surgery

https://doi.org/10.1016/j.jtcvs.2020.07.059
}

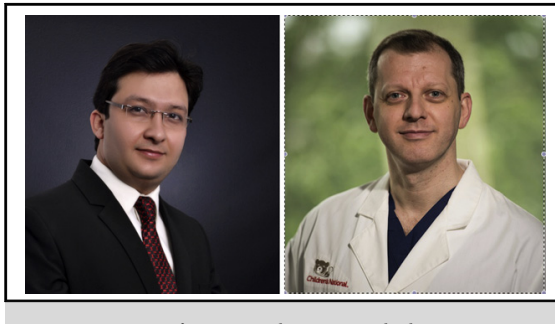

Manan H. Desai, MD, and Can Yerebakan, MD

CENTRAL MESSAGE

Early Fontan failure may be predicted early enough to improve outcomes of patients with single ventricle physiology.

actual postoperative CVP (correlation coefficient of 0.26 ; $P=.03)$. An important caveat to this was that the calculated post-TCPC CVP overestimated the actual postoperative CVP by approximately $7 \mathrm{~mm} \mathrm{Hg}$. The correlation was even stronger in cases without a fenestration. In the second part of the study, they aimed to arrive at a calculated CVP that would predict Fontan takedown. The suggested threshold of predicted post-TCPC CVP of $33 \mathrm{~mm} \mathrm{Hg}$ or more was highly predictive of Fontan failure requiring surgical intervention (fenestration, takedown, transplant) or mortality.

The authors have to be commended for the work on patients palliated with single ventricle circulation. With advances in the field of perfusion, perioperative care, and better understanding of single ventricle physiology, the risk of early failure after staged palliation of single ventricles has been minimized. The risk of early Fontan failure in this series was $5 \%$, which is similar to other reports. The few cases of Fontan failure seen in clinical practice do not necessarily conform to conventional commandments, making prediction of Fontan failure challenging. Patients with normal pulmonary artery resistance and good 